\title{
Anhedonia And the Affectively SCAFFOLdED Mind
}

\author{
ALEX JAMES MILLER TATE \\ King's College London, UK
}

\begin{abstract}
Anhedonia, roughly defined as the diminishment or absence of the capacity to experience pleasure or joy in the performance of daily activities, is a core symptom of Major Depressive Disorder, as well as other psychiatric illnesses. I argue that the two major psychological theories of anhedonia are committed to the view that anhedonia depends, in the general case, on more than just neurobiological states and processes. This is despite the overwhelming explanatory focus on neurobiological factors in the existing literature, which reflects a general commitment to biomedical materialism, the view that mental illnesses are simply neural dysfunctions (Davies 2016; Zachar 2000). Instead, I argue that anhedonia depends upon the breakdown in the function of what Colombetti and Krueger (2015) term a subject's affective niche. Since affective niches are composed of elements of a person's natural and social environments, including artefacts, activities, and other people, anhedonia likewise turns out to depend on a subject's environment, in a manner that makes it generally inscrutable within the boundaries of skin and skull. I discuss and refute some objections to this view, and conclude by sketching a promising, general strategy one could adopt to refute biomedical materialism for a non-trivial class of other psychiatric symptoms.
\end{abstract}

\section{Introduction}

This paper aims to establish that, contrary to the assumptions of much contemporary research, the physical basis of anhedonia is not merely neurological. I begin in this section by specifying what I mean by 'anhedonia' and 'physical basis', and by explaining the details of my thesis. I then outline the strategy that the paper will take to secure it. The paper will close by reflecting on this strategy and evaluating the prospect for it to be generalised across other psychiatric phenomena.

Contact: Alex James Miller Tate <alexander.miller_tate@kcl.ac.uk> 
Anhedonia is a core symptom of Major Depressive Disorder (MDD), amongst other psychiatric conditions (Oyebode 2015). It is broadly defined as "the loss of pleasure or interest in previously rewarding stimuli" (Heller et al. 2009). It is further divided into consummatory, motivational, anticipatory, and decisional sub-types. The first refers to the loss of the subjective experience of pleasure (or positively-valenced affect) from partaking in previously enjoyable activities, the second to a loss of interest or motivation in pursuing such activities, the third to a diminished ability to anticipate future pleasure on the basis of past experiences, and the fourth to difficulties in choosing different courses of action due to indifference regarding their consequences (Mallorquí, Padrao, \& RodriguezFornells 2014; Treadway \& Zald 2011). There is significant debate over whether these four symptoms should fall under the same label (Treadway \& Zald 2011), as they seem to be conceptually and diagnostically separable phenomena (Oyebode 2015: 262, 296). There is, however, some evidence that abnormal activity in certain brain regions ${ }^{1}$ is associated strongly with all of them (Heller et al. 2009), and that MDD patients are vulnerable to each of them (Treadway, Bossaller, Shelton, \& Zald 2012). This notwithstanding, whenever I refer to anhedonia in what follows, I will be speaking about consummatory anhedonia. This is primarily for a pragmatic reason; it is the primary explanatory target of the major psychological theories that I will be examining.

Much contemporary research into anhedonia assumes that its physical basis is wholly neurological (see, e.g., Der-Avakian \& Markou 2012; Rizvi, Pizzagalli, Sproule, \& Kennedy 2016; Treadway \& Zald 2011). That is, it presupposes that anhedonia depends only on neurological processes, or alternatively (and equivalently) that neurological processes alone determine anhedonia. This paper argues that this assumption is unwarranted; existing accounts of anhedonia at the psychological level of explanation imply that neurological processes alone do not determine anhedonia (or at least that they do so only very rarely). I outline my argumentative strategy below, in Section 1.2.

To give a clear example of what I take to be a paradigm case of anhedonia, let me introduce you to Ashley. Ashley has been a very keen marathon-runner for a large part of their adult life. After a hard day at work, Ashley usually likes nothing more than to go for a run. Not only do they enjoy the process of running, but they inevitably feel happier for an extended period after they have returned from a jog.

Recently, Ashley has been diagnosed with MDD. One of the key data points used in this diagnosis was that they no longer enjoy running at all. They no longer have any motivation to go for a run as they once did, and (crucially) even if they do force themselves to go outside for a quick jog, they do not enjoy the

1. Specifically, the nucleus accumbens and frontostriatal network. 
process and feel no better afterwards. As a result of this change and other similar ones, their doctor decided that Ashley exhibited anhedonia.

\subsection{Biomedical Materialism}

It is widely held by psychiatric researchers that MDD is fundamentally a neurobiological disorder, and that its symptoms ultimately have their physical basis in the brain, and perhaps some parts of the wider nervous system (see, e.g., Köhler, Cierpinsky, Kronenberg, \& Adli 2016; Lima-Ojeda, Rupprecht, \& Baghai, 2017; Wohleb, Franklin, Iwata, \& Duman 2016). As Stephan Köhler and colleagues write,

Present theories of MDD ... focus on hyperactivity of the neuroendocrine stress axis ...., impaired cellular plasticity in general and impaired hippocampal neurogenesis in particular ..., perturbations in neurotrophin signalling ..., and neuroinflammation .... (2016: 14)

If this were true, since anhedonia is a core symptom of MDD, it would imply that anhedonia has its physical basis in the brain-again a common position in the literature (see, e.g., Der-Avakian \& Markou 2012; Rizvi et al. 2016; Treadway \& Zald 2011). As Sakina Rizvi and colleagues write,

... we assume that anhedonia can arise from impairments in various facets of reward processing .... Evidence suggests that there are specific neuroanatomical areas that underlie various facets of reward processing, including the prefrontal cortex (orbitofrontal cortex, ventromedial prefrontal cortex and anterior cingulate cortex), dorsal striatum (caudate and putamen), nucleus accumbens and amygdala (2016: 23)

And further,

... anhedonia mechanisms may be a promising area for biomarker research in MDD, since they map onto specific and partially dissociable neurocircuitry and signalling pathways .... (2016:32)

This is simply a representative case of a much wider trend in psychiatric science, which Will Davies (2016), following Peter Zachar (2000) labels biomedical materialism. According to Davies,

On this view, the nature of mental illness is exhausted by neurological properties and events, and all facts about such conditions are scrutable from neural facts. (2016: 291) 
It is important to get clear about the thesis of biomedical materialism, and what it does (and more importantly does not) imply. This view does not imply that mental illnesses are solely caused by neural events, or (perhaps more weakly) that only neural properties/events/facts figure in reasonable causal explanations of such illnesses. The claim is rather one of determination (or vertical explanation); when the death of a loved one causes me to become depressed (as it very well might), according to the biomedical materialist it does so solely by causing certain neural events, and the instantiation of certain neural properties, that fully determine the symptoms of depression.

An instance of this crucial distinction can be seen in the nature of the views proposed by anhedonia researchers. While almost all would accept that anhedonia can easily be caused by repeated exposure to social defeat or other stressors (and exploit this fact to induce anhedonia in animals for experimental purposes), the research they conduct is focused on identifying anhedonia's "neural substrates" (Treadway \& Zald 2011) or the "specific neuroanatomical areas that underlie various facets [of the phenomenon]" (Rizvi et al. 2016: 23). This cannot be charitably interpreted as an attempt to identify anhedonia's causes, because the research presupposes an answer to that question in order to build the necessary animal models (e.g., exposure to repeated social defeat). Rather, what is sought is an answer to the question of what, fundamentally, social stressors are causing when they cause anhedonia. And a typical answer to this question references only neurological facts, mechanisms, and processes. Roughly, stressors cause anhedonia in virtue of causing perturbations to "specific and partially dissociable neurocircuitry and signalling pathways" (Rizvi et al. 2016: 32).

To suggest that a biomedical materialist cannot accept extra-neural causation of mental illness is to commit a variant of what Fred Adams and Kenneth Aizawa have labelled the coupling-constitution fallacy (see Adams \& Aizawa 2001; Aizawa 2010), originally invoked in their opposition to the thesis of the extended mind (Clark \& Chalmers 1998). The charge against proponents of the extended mind is that their arguments demonstrate only that there is a causal relationship between an agent's external environment and their mind, not a constitutive one. That is, our horizontal explanations of mental phenomena (i.e., what brings them about) might rightly involve extra-neural phenomena, but our vertical explanations of them (i.e., what makes them so) should not. ${ }^{2}$

The burden of my argument is to reject this charge-it will fail if it demonstrates only that anhedonia is caused by extra-neural events. Though I do not go so far as proponents of the extended mind, since I do not claim that extra-neural

2. For helpful discussions of the distinction between horizontal and vertical explanations in Psychology more generally, see Roberts (2017) and Drayson (2012). 
things (partially) constitute anhedonia, I do claim that good vertical explanations of anhedonia will involve extra-neural phenomena.

My thesis is that whatever causes anhedonia, it generally does so by causing both neural and extra-neural events, and the instantiation of both neural and extra-neural properties, that only together fully determine anhedonia. This is, roughly, because anhedonia is a diminishment in a certain affective capacity, which is itself fully determined by both neural and extra-neural events/properties/processes.

\subsection{Biomedical Materialism and Psychological Explanations}

In addition to neurobiological explanations of anhedonia (cited above), there are also psychological explanations of anhedonia; that is, explanations that appeal to constructs at the level of psychological, rather than neurobiological, activity. Such explanations of anhedonia generally fall into one of two broad camps. The first of these theorises that anhedonia is constituted by a diminished hedonic capacity, that is, the sufferer is severely limited in the maximum quantity or degree of pleasure they can experience in response to (at least some) stimuli (Fiorito \& Simons 1994; Meehl 1975). Call this the capacity theory. More recently, it has been suggested that anhedonia may instead be constituted by a diminished ability to sustain positive affective responses over time (Heller et al. 2009; Tomarken \& Keener, 1998). Call this the sustainability theory. ${ }^{3}$

If one grants the truth of biomedical materialism (at least in the case of anhedonia), then one needn't think that these psychological explanations of anhedonia are false. Rather, these hypotheses are best interpreted as intermediary explanatory levels on the way to the ultimate, neurobiological underpinnings of anhedonia. That is, accurate psychological theories of anhedonia ultimately reflect only neurobiological facts, properties or dynamics of some sort. On this sort of view, psychological theories of anhedonia are not false; they simply reflect a fundamentally neural process at a relatively high level of abstraction. ${ }^{4}$

Note that it would be bad news for biomedical materialists about anhedonia if it turned out that the psychological factors at play in these theories depend on non-neural properties, events, or processes. If that were true, our best psychological theories of anhedonia would not amount to highly abstracted descriptions of neural events and processes, but would instead entail that anhedonia is determined (at least in part) by extra-neural events, processes, or properties. There would then be a tension between psychological theories of anhedonia

3. Both of these theories seem to have their origin in Myerson (1922).

4. For an investigation and sustained critique of this kind of neuro-centrism in Psychiatry more generally, see Huber \& Kutschenko (2009). 
and the neurological reductionism of the biomedical materialist. They would be forced to either disavow the psychological theory in question, or disavow their biomedical materialism. Since the first option would entail disavowing reams of empirical evidence on the basis of little more than philosophical conviction, it seems as if the philosophical assumption should be the one to fall.

My claim in this paper is precisely that both of the most popular psychological theories of anhedonia entail this kind of dependence on extra-neural events, processes, and properties. Whichever psychological account of anhedonia one chooses, the psychological abnormality posited is best understood as a breakdown of functionality in what Colombetti and Krueger (2015) call an individual's affective niche. Just what kind of breakdown I have in mind, and what an affective niche is, will become clear in what follows. It will suffice for now to note that, if I am right, then both theories suggest that anhedonia's ultimate physical basis a) is likely to be different from case to case and b) will in the general case include elements of an individual's material and social environment. Entirely neurobiologically grounded instances of anhedonia will turn out to be (at best) rare limit cases of a disorder that typically exhibits dependence on interactions between agents and their environments.

My argument will proceed in two main stages. In the first, I shall argue that the psychological capabilities hypothesised to be diminished in anhedonia by the capacity and sustainability theories are best understood as variable across contexts and significantly dependent on environmental resources available to the agent. In the second I shall argue that this suggests that the ultimate physical basis of anhedonia is neither uniform, nor generally to be found in the brain. These arguments will be made in Sections 4 and 5 respectively. Neither of these claims, it should be emphasised, imply that anhedonia's physical basis is not generally partially to be found in the brain, nor that this partial contribution of neurology is unnecessary. Indeed, I believe that the brain plays a necessary role in grounding anhedonia, as it does all psychological phenomena. But it is not the whole story. At the end of Section 5, I will reflect on this strategy, generalise it, and reflect on its virtues compared to other attempts by externalists and situated cognition theorists to reject biomedical materialism.

Before I argue for these core claims in Sections 4 and 5, however, I must introduce and explain several key concepts that the arguments will depend on. In Section 2 I shall introduce and explain the capacity and sustainability theories, focusing on the psychological capability each hypothesises to be diminished or otherwise disrupted in anhedonia. And in Section 3 I shall introduce and explain two key ideas from the situated cognition literature-affective scaffolds (Colombetti 2017; Colombetti \& Krueger 2015; Griffiths \& Scarantino 2009) and the construction of a cognitive/affective niche (Colombetti \& Krueger 2015; Sterelny 2010). 


\section{Two Theories of Anhedonia}

In this section I shall explain the two main competing psychological theories of anhedonia and briefly review some of the main empirical evidence available for each. The crucial take away from this section will be that each posits a diminishment or loss of a distinct psychological capability. In the case of the capacity theory, this is the capability of experiencing a particular maximum amount of positive affect. In the case of the sustainability theory, this is the ability to sustain positively valenced affective responses (henceforth 'positive affect') over time. These capabilities will be the targets of analysis in the rest of the paper. An easy (though rough) way to think about this distinction is that the capacity theory holds that anhedonia is about diminished affective intensity, and the sustainability theory that it is about affective duration.

\subsection{Capacity Theory}

For many years the dominant psychological theory of anhedonia, which still has many defenders, was very simple; people with anhedonia suffer from a diminished hedonic capacity (Meehl 1975; Pizzagalli, Iosifescu, Hallett, Ratner, \& Fava 2008). Hedonic capacity is supposed to refer to the maximum amount of positive affect a person is capable of experiencing in their day-to-day life. According to the capacity theory, anhedonia is a matter of the cap on this maximum amount of pleasure being significantly lowered. An anhedonic person is simply unable to ever experience the amount of pleasure that a non-anhedonic person can, and consequently fails to experience the same amount of pleasure from certain activities as they used to.

Imagine a pint glass filled with water. The maximum capacity of the glass is the maximum amount of pleasure a person can experience from a given activity. The basic claim of the capacity theorists is that an anhedonic person's glass has been replaced with a thimble. In Ashley's case, this amounts to a claim that they are no longer able to experience the same amount of pleasure from running as they once did; the maximum cap on the pleasure they are able to experience from running (and probably, though not necessarily, other activities) has been significantly lowered.

Some data seem to support this theory. It has been found that anhedonic people report that they find positive images less positive, and that both positive and negative images are less impactful on their emotional state, than those without anhedonia (Fiorito \& Simons 1994). Visceral physiological (heart rate change) and overt behavioural measures (facial expression) of emotional arousal have also been found to be diminished in anhedonic people (Fiorito \& Simons 1994). That said, these data have not proven to be easily reproducible (Germans 
\& Kring 2000; Kaviani, Gray, Checkley, Raven, Wilson, \& Kumari 2004). Given this, some researchers have sought support for an alternative hypothesis.

\subsection{Sustainability Theory}

Several studies suggest that the issue in anhedonia may not be one of hedonic capacity, or at least not solely (see Heller et al. 2009). The sustainability theory suggests that anhedonic individuals are capable of experiencing the same peaks of enjoyment as the rest of us. The problem is that the ability of an anhedonic individual to sustain a pleasurable or joyful response to certain stimuli is impaired (Heller et al. 2009; Tomarken \& Keener, 1998). The claim here is that pleasurable reactions to stimuli are typically significantly temporally extended, but in anhedonia the length of time positive affect continues is diminished.

Imagine the glass again. According to sustainability theorists, the problem in anhedonia is not the size of the glass, but its ability to hold the water that is poured in. A healthy person's glass will hold all or nearly all of the water it can for an appropriate length of time. An anhedonic person's glass, on the other hand, is tremendously leaky. Returning to Ashley, the sustainability theorists suggest that what is going on is not as simple as it might have initially appeared. Although Ashley's ability to receive pleasure from the initial act of running may be relatively undiminished, their ability to feel good throughout the course of the run and afterwards is significantly impaired. As a result, Ashley does not experience the run as being enjoyable in the way they once did, as the experience is no longer sufficiently temporally extended.

An FMRI study by Heller and colleagues (2009) supports this idea. Areas of the brain associated with reward processing and regulation of positive affect "showed a specific decrease in activation [in response to positive stimuli] . . . across time, while control subjects maintained their level of activation" (Heller et al. 2009: 22448). Moreover "the amount of decrease in . . . activity across time predicted overall self-reported affect" (2009: 22448). Further, Liu and colleagues (2011) have demonstrated that anhedonia in MDD reflects an inability to sustain behaviour directed towards salient incentives over time. They take this to (broadly) support the sustainability theory, assuming ongoing positive affect's role in sustaining reward-related behaviour over time.

So we have identified two psychological capabilities, the diminishment of which are hypothesised to characterise anhedonia - the in/ability to experience particular 'highs' of positive affect, or the in/ability to sustain positive affective responses over relatively extended time periods. These are, to my knowledge, the main contenders. Some may think that they each specify a real, though distinct, symptom that are conflated to the single concept of (consummatory) anhedonia. Others may think that (consummatory) anhedonia is a unified phenomenon, but 
is instead characterised to different degrees by both of the diminished capabilities hypothesised. These nuances are not important in what follows. The goal in Section 4 will (roughly) be to argue that, whichever diminished psychological capability (or capabilities) one takes to characterise anhedonia, it turns out to depend significantly on particular kinds of environmental resources.

Of course, it is possible that a new theory will emerge that claims that a novel psychological capability, call it $c$, characterises anhedonia instead. If $c$ turned out not to be interestingly dependent on environmental resources, then this theory would be a refuge for those who wanted to insist on a neuro-centric view of anhedonia, though of course properly 'joining up' the neurobiological and psychological levels of explanation in a suitably comprehensive manner would still involve numerous problems. That said, I do not think that it is incumbent on me to argue on behalf of imaginary theories. Readers concerned by this possibility may think of my eventual claim (in Section 5), that anhedonia is not entirely neurobiologically grounded, as being implicitly conditionalised-it holds if either (or both) of the currently popular psychological theories of anhedonia are correct.

\section{Situating Affect \& Affective Niche Construction}

One of the unifying claims of the situated emotion research literature is that resources in the environment (natural, social, and cultural) of the agents (whether intentionally made available by the agent themselves or otherwise) are indispensable for the development and realisation of particular affective competencies. Call resources that exhibit this quality affective scaffolds (Colombetti \& Krueger 2015; Griffiths \& Scarantino 2009). Another common claim is that there is often a relationship of reciprocal influence between agents' affective competencies and affective scaffolds. That is, a particular resource may enhance an agent's (or many agents') affective capabilities in such a way that it leads to the development or availability of new scaffolds, which in turn may further enhance some aspect of an agent's affective life. Call contextually or universally available collections of affective scaffolds to which we become accustomed (and that which may often emerge in their entirety as a result of the aforementioned kind of reciprocal influence) affective niches (Colombetti 2017; Sterelny 2010). It is to fleshing out these concepts that I turn in this section.

\subsection{Functional Gain and Reciprocity}

We can intuitively distinguish between those conditions or resources that provide necessary background to the execution of some function, and those that are 
actively recruited into the process of executing that function; those that merely enable some capacity and those that genuinely enhance its realisation in some way. The presence of oxygen falls into the first camp with respect to most cognitive capacities. There is no obvious sense in which the kind of potential impediments to living that cognition exists to overcome need ever involve recruiting oxygen as a resource directly, though certainly no cognitive problems can be usefully resolved if the brain is starved of oxygen. Another example: I cannot win a game of chess if the sun explodes shortly before I start playing (my opponent's and my being dead, along with the lack of non-atomised chess boards being great impediments). Nevertheless, we rightly do not speak of a non-exploded sun as being a resource that I recruited, or made use of, in order to win. It is not this kind of trivial dependence of cognitive capabilities on external resources that I am interested in for the purposes of this paper.

I am interested in cases where the execution of certain cognitive functions seems to actively make use of resources, information, and structure external to the organism. For instance, skilled bag packers in grocery stores in the USA often arrange items spatially by category (heavy, light, fragile, etc.) as they come off the conveyor. This is to subsequently facilitate optimal packing arrangements, while not placing an unbearable load on working memory-one need not remember how heavy each individual object was if all the heavy and light objects have been placed in distinct and mentally labelled regions of space (Kirsh 1995, cited in Robbins \& Aydede 2009: 6). Here, we see external spatial resources being deployed to lessen the need for substantial internal memory resources to be used in the execution of the task. Moreover, in the case of there being some very large number of items, it is sensible to suppose that optimal bag-packing could not be accomplished without recruiting the relevant spatial resources (or some functional analogue that goes beyond bio-memory). The fact that the space exists, and humans are able to interact with it in a particular way (and do), produces a functionally significant improvement in a particular cognitive ability. In short, interaction with the environment in particular ways enhances cognitive capacity.

Theorists in the situated cognition camp argue that these kinds of cases are the rule rather than the exceptions. Most important cognitive tasks are resolved at least in part thanks to the recruitment of pre-existing environmental structure, or the active construction of it (both are present in the bag-packing case). This bears a strong similarity to what Lawrence Shapiro labels the Principle of Ecological Assembly:

problem solving ... is a function of the resources an organism has available to it [or can readily make available to it] in its surrounding environ. (2011: 63, additions mine) 
It is crucial to note however that, on the situated picture of cognition, not only problem solving, but the capacities that enable it, are functions "of the resources an organism has available to it [or can make available to it]" (2011: 63, additions mine). The capacity of the bag-packers to perform their task is enhanced by the availability and exploitation of surrounding spatial resources. And many of our most core cognitive capacities are enhanced by such externally located resources (much of the time ones that we have developed or arranged ourselves for precisely that purpose). We enhance our perceptual capabilities with binoculars, our mathematical reasoning capabilities with calculators, our navigational capabilities with maps, and so forth (Sterelny 2010). To give the phenomenon a name, some external resources scaffold functional gain in our cognitive abilities; they grant us particular cognitive abilities that we would not otherwise possess, or deliver significant enhancement, such that our cognitive capacities would be seriously impoverished without them. Call such items cognitive scaffolds. Some cognitive scaffolds, like in the examples I have given, scaffold our cognitive capacities in particular instances, over the relatively short-term. Others, such as written language, plausibly enhance our cognitive abilities across the course of our development and indeed across generations (Wilson \& Clark 2009). Call the latter kind diachronic cognitive scaffolds and the former synchronic cognitive scaffolds. ${ }^{5}$ Moreover, while some cognitive scaffolds are common to us all (or almost all of us at least), some are highly specific to individuals. And we actively shape our environments and the resources within it so as to have particular kinds of cognitive scaffolds available when they are needed, both generic and highly specific-many of us carry binoculars with us when we know we may have to see great distances and mark maps with routes and scribbles that are unique to our own navigational needs.

External resources scaffold functional gain in our affective abilities as well (in the discussion that follows I draw predominantly from Griffiths \& Scarantino 2009 and Colombetti \& Krueger 2015). Maintaining a reasonable mood is a capability many of us enjoy, but our strategies for achieving it are often dependent on the presence of certain kinds of external resources. Examples include cigarettes, music players, gentle lighting, scented candles, other people, or vacations. Different people exhibit different patterns of individuality, reliance, and trust with respect to the affective scaffolds they make use of. Our music players for instance tend to be highly individualised artefacts, representing our particular taste in music, with particular playlists often deliberately designed to achieve different

5. Here, I shall make my case via examples of synchronic scaffolding. This is not because I think affective capabilities are in general only synchronically scaffolded, or that anhedonia has nothing to do with diachronic scaffolding. Both of these claims are, in my view, almost certainly false. But such discussion will complicate matters, and thus impede rather than enhance understanding of the basic idea being presented. 
affective ends for us (music that 'pumps us up' for exercise, music that relaxes us, music that makes us happy, music that helps us cry, and so forth). We may not rely on a yearly holiday for a positive temperament nearly as much as we do a weekly drink with our friends-the loss of the latter may put us entirely out of sorts whereas we can more-or-less cope without the former. And we may trust our cigarettes to perk us up considerably more than a nice healthy walk in a park (or vice versa). The upshot is that the presence of any of these things may enhance our ability to exhibit, regulate or maintain particular affective states, and their absence may significantly impede these abilities. This enhancement may occur over many timescales-social norms regarding suitable emotional displays at funerals or birthday parties may significantly affect the development of our situation-sensitive emotional repertoires and constrain immediate emotional range where necessary. And the specific collection of emotional concepts and words that we possess - due to both individual developmentally significant experiences and cultural influence-may affect our actual emotional experiences in the moment, by affecting how we view, categorise, and interpret them, as well as how they are used to guide behaviour (Barrett 2012; 2014).

Crucially, affective scaffolds cannot be reduced to elicitors of emotion or emotional stimuli. The first reason is discussed above-certain of our affective abilities may be impaired without momentary or sustained support from an affective scaffold. They are active contributors to the qualities of our emotional life, rather than simply triggers of it. We would not possess many of the affective abilities we do were it not for the presence of a suitable collection of scaffolds at appropriate times. The second reason is that the contribution is not unidirectional-we shape and create affective scaffolds just as much as affective scaffolds shape and create our affective capacities, and often in virtue of their previous contributions. Some of us deliberately construct the contents of our music players to reflect a range of affective needs we may have, and carry them with us regularly enough that they are reliably available when those needs arise. Others of us design our ideal homes, and decorate particular rooms so that they have relaxing or energising qualities. Sometimes the contribution of one affective scaffold may help us to recruit the contribution of another; for instance, I may listen to calming music when I am very anxious about an upcoming exam, precisely so that I am able to call my friend and discuss the problem with them. Had I not listened to the music first, the friendly discussion route may well not have been open to me, because my high levels of anxiety could have prevented me from communicating sufficiently clearly, or plucking up the courage to even pick up the phone.

This entire discussion invites the following question; what exactly is the nature of the relationship between scaffolds on the one hand, and cognitive/affective capabilities on the other?

Before we attempt to answer this question, note first that the interesting 
question here is not one of the relationship between scaffolds and cognitive/affective events. This paper is wholly concerned with affective capabilities, not single affective events or experiences, simply because anhedonia is not (according to either the capacity or sustainability theory) characterised by specific affective events, nor by their absence. Rather, it is characterised by diminished or absent affective capabilities; the maximum pleasure one can experience in the case of the capacity theory, and the length of time such experiences can be sustained in the case of the sustainability theory. The distinction here is directly analogous to that between a glass shattering (an event) and its disposition to shatter (a standing state). Affective capabilities are dispositional in the sense that they figure in explanations of events, and can even be necessary conditions for them, but are not themselves events.

Having clarified the question then, what is the answer? One suggestion might be that affective scaffolds cause affective capabilities. But this seems wrongcausation is typically thought to proceed across time, but the claim of situated cognition theorists is not that the presence of certain affective scaffolds at t1 produces a certain affective capability at $t 2$. Rather, the idea is that at $t 1$, the presence of the right affective scaffolds ensures a corresponding affective capability.

An alternative is that affective scaffolds partially constitute affective capabilities. I suppose this might be right, but it is a very strong claim in need of significant argument. Here is just one major impediment to giving such an argument; it is very natural to think of our capabilities as being fundamentally constituted by (in some sense) parts of $u s-$ my ability to throw a ball is constituted by states of my shoulder muscles and processes in my motor system. But my environment is surely not part of me; this just seems to be part of the definition of what it is to be my environment. So how could features of my environment even partially constitute any of my capabilities? It is also noteworthy that Colombetti and Krueger (2015) explicitly disavow this interpretation. They write (regarding the view that cognition is scaffolded) that,

This is an intermediate position along a dimension of other possible stances .... At one extreme of this dimension is the internalist position according to which the mind supervenes on the brain only ... at the other extreme is the externalist view according to which the mind is necessarily constituted by the environment .... (Colombetti \& Krueger 2015: 1159).

So, the two most obvious suggestions do not obviously work. What else might we say? I cannot provide a full answer here, but I think that the most plausible suggestion is that the relationship between affective scaffolds and affective capabilities is directly analogous to the relationship between the presence of oxygen in an environment and the disposition of a match to ignite when 
struck in that environment. The less oxygen there is, the less disposed the match is to ignite, and if there is sufficiently little oxygen, it cannot do so at all. Here, the disposition of the match to ignite depends on the amount of oxygen in the atmosphere, but is not plausibly caused or constituted by it. Likewise, the fewer of the right kinds of affective scaffolds that exist in a person's environment, the less able they are to exercise their affective capabilities, and if there are sufficiently few, they cannot do so at all. Affective capabilities depend on affective scaffolds, but are not caused or constituted by them.

\subsection{Constructing and Deconstructing Affective Niches}

If we agree that affective capabilities typically depend on affective scaffolds, then the upshot is that people are constantly engaged in an active, ongoing relationship with the world, and the individual, and often unique, contributions of their brains, bodies, and environment to this relationship collectively determine certain affective capabilities that would be unachievable without one or another of the components. Given humans' propensity to actively shape and choose (to some degree) the worldly dimension of this distributed affective network, we may say that humans occupy partially generic and partially individualised affective niches for much of their lives. That is to say, we build and select affectively relevant artefacts, people, and locations for the sake of their abilities to make helpful contributions to our affective lives. These niches are generic insofar as certain social norms, cultural understandings, and architectural designs, etc. (all of which may count as affective scaffolds) are shared amongst all, or nearly all, people who occupy a particular country, community, or city. But they are also individualised to the degree that individuals make choices and take actions regarding the kinds of affective scaffolds they make use of, or carry with them, on a day-to-day basis. Naturally, we occupy many niches throughout our lives, and some scaffolds are more-or-less permanent fixtures in all of them, for a variety of reasons. And when we do occupy different niches, which enable correspondingly different affective abilities, everything from our comportment, to our manner of speaking, to our capacities for emotional regulation may change (Colombetti \& Krueger 2015: 1169).

These variances can help to maintain, or destabilise, particular affective niches, or our connections with particular affective scaffolds. For instance, our sense of humour, distinctive as it is of particular kinds of social setting, may help to maintain our friends and colleagues as affective scaffolds. Yet if you go to a gathering of strangers and the close friend you expected to be there does not show up, not only might your emotional regulatory capabilities be initially diminished, such that you exhibit high degrees of anxiety and nervousness, so might this propensity further impoverish the affective niche in which you find 
yourself (if the others around you are uncaring, or misinterpret your anxiety as rudeness or indifference, for example). The absence or unavailability of one affective scaffold may precipitate further diminishment in one's affective capabilities until they are severely impoverished.

The main points to take away from this section are threefold. Firstly, our affective capabilities, in general, depend on various different kinds of affective scaffolds that exist across multiple timescales. Secondly, various factors may contribute or detract from particular affective scaffolds' availability to us in any particular situation, such that our affective capacities are correspondingly enhanced or diminished. And thirdly, there is often a relationship of reciprocal dependency between the affective capabilities dependent on certain affective scaffolds (or combinations of them) and the affective scaffolds themselves, which may result in both upward and downward spiralling of affective capabilities when otherwise stable affective niches are perturbed or otherwise altered in some way.

None of this is to say that the brain does not make significant, indeed invaluable and to some degree irreplaceable contributions to our affective capabilities. But it does suggest that our affective life in general-the particular affective capabilities we possess and exhibit - does not have its physical basis solely in brain activity. To the extent that elements of our own unique affective niches make both long- and short-term contributions to the extent and existence of particular affective capabilities (such that if they were removed, such capabilities would either diminish in their potency, or cease to be exhibited altogether), the physical basis of affect is not simply locatable within the boundaries of skin and skull. In the next section, I shall argue that this is true of the two specific affective capabilities hypothesised to be at the core of anhedonia.

\section{Situating Hedonic Capabilities}

We can already see how the framework sketched above might influence our view of anhedonia. The basic picture I want to offer is as follows. A whole range of changes might render some people significantly less or even unable to experience pleasure throughout the course of their day-to-day lives. These changes range from straightforwardly neural ones, to changes in a person's affective niche; for instance, the closing of a football club where they used to enjoy exercising in the evening, the breaking of a person's $\mathrm{MP}_{3}$ player, or losing contact with a close friend or family member. Once somebody is rendered unable, or significantly less able, to experience pleasure, they may withdraw further from social life, and other situations that they previously sought out for the sake of enjoyment (e.g., listening to music or playing videogames). This behaviour might easily lead to them falling temporarily or permanently out of contact with people whom they 
previously enjoyed being around, and all of these changes can be expected to further diminish their ability to experience pleasure. Conversely, someone who struggles to experience pleasure (for whatever reason) might nevertheless have this capability somewhat enhanced by their friends making concerted efforts to maintain contact, and arranging activities which are easy for them to participate in. This is simply to say that 1 ) the affective niche of somebody who has anhedonia is likely to be seriously impoverished, in a way that sustains and may worsen their condition (even if it was not a change in this niche that initiated their decline), and that 2) someone with anhedonia can have the severity of their condition lessened (though probably not eliminated) by interventions that aim to sustain, replace, or rebuild elements of their affective niche that have been lost. All of this suggests that anhedonia exhibits significant dependence on the features of an individual's affective niche.

Naturally, this vignette is a little too vague to count as an argument for my main claim. In particular, the notion of an 'ability to experience pleasure' needs to be refined, lest we smuggle in unwarranted assumptions or equivocations. Refining the nature of this capacity is precisely what the two main psychological theories of anhedonia attempt to do. My aim will be to demonstrate that both of these purported refinements exhibit significant (though partial) dependence on an individual's affective niche.

To clarify, in this section I shall argue for the following claim:

[Niche-Dependent Capacities] Whether you endorse a capacity or sustainability theory of anhedonia, the relevant capabilities (of which anhedonia is taken to be a diminishment or loss) are, typically, the partial outcome of functional gain reliant on external affective scaffolds forming an adaptive affective niche.

Let's unpack this claim (NDC). The capacity and sustainability theories each posit that different affective capabilities are characteristically diminished in cases of anhedonia. The capacity theory posits that this capability is that of being able to experience relevantly high quantities of pleasure. When people experience anhedonia, according to the capacity theory, they are experiencing diminished overall hedonic capacity - they just can't experience as much positive affect as they used to. ${ }^{6}$ The sustainability theory posits the same thing regarding the

6. Depending on your favoured view of the nature of illness, you might think that what is important is not what a person used to be like, but rather how they compare to a statistically or normatively defined comparison population, or how they fare in comparison to what they would need to meet their life challenges. Nothing in this paper hinges on what we think about this issue. See Law \& Widdows (2008), Bircher (2005), and Kovacs (1998), for some opinionated overviews of positions on the nature of health and illness. 
ability to maintain highs of positive affect over time after coming into contact with positive stimuli-call this hedonic sustainability. My goal in this section is to argue that both hedonic capacity and hedonic sustainability are, in general, partially dependent on the characteristics of the affective niches (with a view to both long and short timescales) occupied by the relevant individual. In short, my goal is to argue that they are situated psychological phenomena.

\subsection{Situating Hedonic Capacity}

I begin with hedonic capacity. Recall that hedonic capacity is defined as the maximum amount of positive affect a person is capable of experiencing. Our question is simply this; what determines an individual's hedonic capacity?

It might be tempting to think that the answer is simply genetics (or the genome's phenotypic expression in brain and nervous system structure), and indeed hedonic capacity does appear to be partially so determined (Dworkin \& Saczynski 1984: 623-624; Meehl 1975). But there is pretty clear evidence from twin comparison studies that the developmental environment plays a large role as well (Dworkin \& Saczynski 1984: 623-624). That is simply to say that an individual's hedonic capacity is co-determined by genetic and developmental factors. Unfortunately, however, this is not on its own a wholly convincing consideration in favour of the idea that hedonic capacity is scaffolded by functional gain dependent on external affective resources.

The reason for this is simple-it could be that the developmental environment has an impact on brain development that partially determines overall hedonic capacity (see Sonuga-Barke 2017). If it turned out that the phenotypic expression of the genome and developmental impact on the brain completely co-determined an individual's hedonic capacity, then an opponent to my view could claim that hedonic capacity had its physical basis in the brain; it would just be that this physical basis arose from a variety of sources. And if, once established, this physical basis (and indeed one's hedonic capacity) was relatively invariant, their case would be even stronger - there would appear to be no indispensable need to reference the wider environment in vertical explanations of an individual's hedonic capacity.

Fortunately, there are other reasons to believe in strict partial dependence of hedonic capacity on affective scaffolds. Imagine you spend much of any given day plugged into a mp3 player, or that you get together with your friends at the weekend to play board games.

Take the first case. Imagine you go for a walk one day and forget your $\mathrm{mp}_{3}$ player. The effect is likely not to simply be frustration, you may find throughout the day that you are just ever so slightly (or indeed significantly) less happy than you would have been had you had the mp3 player-and if this is not the 
case it is likely because you have found some other activity or resource in the environment that is able to play the same overall affective functional role (you have adapted your affective niche to manage the change). That is, the mp3 player is plausibly thought of as typically enhancing your moment-to-moment hedonic capacity, and its absence has an effect on your mood throughout the day and, crucially, your ability to enjoy the rest of the day's activity as much as you might otherwise have done. It is only by adapting one's affective niche that one can restore hedonic capacity to what it was. This suggestion is far from merely speculative-Skånland (2013) provides qualitative evidence of mp3 players' utility, and sometimes utter indispensability, in intensifying individuals' day-today positive affective experiences.

Take the other case. Imagine your friends all cancel on you at short notice for one weekend's board game extravaganza. You may not be particularly angry or upset (they all have very good reasons not to attend, and you react to them appropriately). Nevertheless, you may find that the rest of the day just isn't quite as bright as it might otherwise have been. Again, rectifying that will involve finding some other resource in the external environment capable of making the same affective contribution as playing board games would have done. Without something along those lines, you are just not quite as able to experience the heights of positive affect as before. It's not just the enjoyment of the games themselves you miss out on, but the general improvement in mood the whole experience facilitates.

Neither of these cases are ones where we can plausibly link diminished hedonic capacity to structural changes in the brain. The changes are simply too quick and immediately associated with alterations or perturbations to an affective niche. It is much more plausible to account for the change directly in those terms. It's important to note that nothing about the above examples necessitates that the diminishment in hedonic capacity be particularly severe. It may not even be particularly obvious to the person experiencing it unless they reflect on it. The point is only that small alterations in affective niches can quickly precipitate diminished hedonic capacity. This is enough to suggest that elements of our affective niche typically scaffold functional gain in our hedonic capacity. That is, our hedonic capacity is typically greater than would be possible without suitable environmental resources.

Further, the general idea that the environmental resources one has access to at a given time affects one's hedonic capacity has empirical support. Stressful environments (typically ones in which one is deprived of many normal affective scaffolds in one way or another-including military service and college exam periods) have been found to diminish individuals' hedonic capacity across a number of scales of measurement (Berenbaum \& Connelly 1993; Pizzagalli, Bogdan, Ratner, \& Jahn 2007). And people seem to use established interpersonal 
relationships to enhance their hedonic capacity when in social groups (Gable \& Reis 2010). The key takeaway here, and in this section as a whole, is that one's hedonic capacity is not stable, or fixed, but significantly dependent on material and social circumstance. A given individual's hedonic capacity is achieved in significant part through functional gain scaffolded by elements of the affective niches that they inhabit.

\subsection{Situating Hedonic Sustainability}

Let us move on to hedonic sustainability. A useful way of conceiving of this capability is as a form of emotional regulation. Koole defines emotional regulation "as the set of processes whereby people seek to redirect the spontaneous flow of their emotions." (2009: 6). Given this way of thinking, hedonic sustainability is about the processes used to 'redirect the flow' of positive affect away from positive valence, in the sense that it is about preventing positive affective experiences moving towards more neutral (or even negative) states. It is about how people 'keep themselves going' once they are already undergoing a positive affective experience. The goal of this section is to argue that many of these processes are distributed across individual's environments, and thus that an individual's capability for hedonic sustainability is typically partly dependent on affective resources located in the environment. This is just to say that affective scaffolds enhance an individual's capability for hedonic sustainability.

Theorists have argued persuasively that emotion regulation in general is scaffolded by environmental resources both material and social (e.g., Colombetti \& Krueger 2015; Koole \& Veenstra 2015). They have significant empirical support too. Actions (both conscious and unconscious) of caregivers, and subsequent interaction, enormously enhance the emotional regulatory capacities of infants (Manian \& Bornstein 2009; Varga 2016), and there is significant evidence that these sorts of processes continue between people and their friends and family throughout development and adulthood (Zaki \& Williams 2013). Linguistic expression seems to enormously enhance emotional regulatory capabilities, as a result of enabling both emotional communication (Burleson 1985), and simply emotional articulation (Lieberman 2011; Samur, Tops, Schlinkert, Quirin, Cuijpers, \& Koole 2013). People's ability to redirect their emotional experiences is also tremendously enhanced by a variety of material resources and activities including hot showers for alleviating loneliness (Bargh \& Shalev 2012), cuddling soft toys or seeking interpersonal touch for down-regulating existential anxiety (Koole, Sin, \& Schneider 2014), and seeking out and utilising cleaning products to down-regulate disgust (Koole, Webb, \& Sheeran 2015; Vogt, Lozo, Koster, \& De Houwer 2010).

So it is fair to say that the evidence in favour of emotional regulation being 
a significantly environmentally scaffolded capability is strong. This does not, however, necessarily imply that the ability to sustain positive affect is specifically scaffolded in this way. Fortunately, we can make a case for that as well.

The first example will involve music again. Many people use it during workouts, mostly via portable music players, to enhance their ability to complete an otherwise gruelling regimen of physical exercise. It is natural to think that one significant task involved in motivating oneself to continue a workout is to maintain a positive affective state as consistently as possible throughout the regimen. Studies have shown not only that listening to music enhances positive affect throughout periods of exercise (Elliott, Carr, \& Savage 2004), but that it helps to maintain it during the workout (Lim, Atkinson, Karageorghis, \& Eubank 2009), and lengthens the time post-workout during which people continue to experience elevated affect (Elliott, Carr, \& Orme 2005). To the extent that we take such research seriously, it would appear that music players significantly enhance people's degree of hedonic sustainability during exercise. Moreover, for many people, other kinds of stressors other than exercise are also made more manageable, and thus hedonic sustainability enhanced, through the consistent availability of music throughout the day (Skånland 2013).

There is also evidence that these sorts of enhancements are not limited to the domain of exercise. For instance, maintaining the right kind of positive affect over the course of a day is often achieved through selection (entirely deliberate or otherwise) of the right clothing or accessories at the beginning of it. Everything from the colour, to the texture, to the overall appearance of clothing seems to play a role in helping us to maintain a positive mood in the face of daily stressors (Kwon 1991; Moody, Kinderman, \& Sinha 2010; Valdez \& Mehrabian 1994). This is also clearly reflected in our language-we describe colours as 'calming' and entire outfits as 'powerful', amongst other things. So hedonic sustainability is also seemingly enhanced by clothing selection.

These are just a few examples of items of material culture scaffolding hedonic sustainability. Here is one more. On a night out, one's perceived energy levels and sense of continued enjoyment may be sustained through the use of cigarettes or alcohol (or indeed other, more interesting, substances). Moreover, this effect cannot easily be reduced to the chemical composition of these substances - simply the ritual of indulging in them, in a particular environment, with a particular group of people may help to sustain positive affect through exhaustion. Many of us are familiar with the phenomenon of becoming 'drunk on atmosphere'. This is simply to say that the scaffolding effects of these substances in certain contexts have a marked intersubjective quality.

So it seems as if material items and their associated cultural rituals are often recruited into the processes invoked to sustain positive affective experiences over time. There are of course numerous other examples beyond what I sug- 
gest above. Nevertheless, those examples are suitably representative to make my point.

Hedonic sustainability also exhibits a similar relation of dependence upon interpersonal (or social) scaffolds. It is a common enough experience that after a while of not interacting with other people, even individuals who are otherwise doing well begin to experience a dip in mood and general demeanour. Isolation is a powerful force for dysregulating positive affective responses, seemingly regardless of intervening stressors.

Going beyond intuitions, studies indicate that interpersonal interaction is a major mechanism of both general positive affect maintenance and the prevention of negative emotional spirals in the presence of stressors (Zaki \& Williams 2013), as well as being a proposed (and well-supported) mechanism by which social support acts as a protective mechanism against onset of depression (Marroquin 2011). This is achieved in at least two ways: through the simple recognition that the affective resources of another person are available to react to a particular stressor (Zaki \& Williams, 2013: 806) and via recognition that some experience is understood and shared by another person (Zaki, Schirmer, \& Mitchell 2011). Both of these methods permit a degree of stability in one's positive affective experiences that would otherwise be difficult or impossible to obtain, as evidenced by the strong predictive relationship between absent or maladaptive social support and mood disorders in general (Hofmann 2014: 490-491). This idea is further supported by an argument provided by Somogy Varga and Joel Krueger, to the effect that pairs of humans in close relationships (child-caregiver as well as adult-adult) exhibit synchronization of bodily movements, which acts as a mechanism of distributed emotion regulation (2013: 287). Studies of the regulatory dynamics of romantic partners (e.g., Saxbe \& Repetti 2010), as well as emotional dysregulation following the death of a close partner (e.g., Sbarra \& Hazan 2008), seem to provide confirming evidence for their picture. Thus, it seems likely that interpersonal regulation scaffolds functional gain in hedonic sustainability.

The upshot of this section is that people actively contribute to the construction of affective niches, by creating, carrying with them, and consistently engaging with a variety of material and social scaffolds of affective capabilities. Moreover, from the composite elements of these affective niches spring a significant part of people's hedonic capacity and hedonic sustainability (both relative to a given situation, time and place). Thus, whichever affective capability one believes to be diminished in anhedonia, that capability is, in the general case, partially dependent on engagement with environmental resources. That is just to say that the given capability will typically have part of its physical basis in the environment, and part in the activity of a person's brain and nervous system.

Some might say that I have not yet established that the environment per se makes an ineliminable determining contribution to the relevant affective capa- 
bilities. Rather I have established that in any given case, either the environment makes such a contribution or an individual's ability to create and use the right kind of environmental resources makes such a contribution. This distinction matters, so the objection would go, because if the affective capability diminished in anhedonia only depends on the latter, and not the former, then the biomedical materialist might be able to account for the subject's failure to create scaffolds in their own terms. They could say, for instance, that an individual has a neurological deficit that undermines motivated action or seeking behaviour, and that the resultant failure to build and maintain their affective niche fully explains their diminished affective capability. That is, the role of the environment is eliminable because it is mediated by fundamentally neural processes, properties, or events. 7

I do not think this worry need concern us too much, for at least two reasons. Firstly, my claim is not that people with anhedonia necessarily have niches that are absent of affective scaffolds (such as opportunities to go running or music players), or have fewer of them. My claim is that these scaffolds cannot play their ordinary role in enhancing the relevant affective capability. This could be for all kinds of reasons; perhaps an individual is unmotivated to make use of them (e.g., a depressed person could go to football practice but fails to get out of bed), or perhaps a previously available scaffold becomes unavailable (e.g., the price of football practice becomes too high, or a close friend moves to a distant country), or perhaps a person fails to create a scaffold they would otherwise have had (e.g., they fail to make a playlist for travelling to and from work). This point is crucial, because only some of these cases are plausibly thought to depend on an individual's exercising their agency, rather than strictly depending on what is in the environment to be made use of. Since I have defended the view that the affective capability implicated in anhedonia depends on features of the environment playing this sort of role (and not on them playing this role in any particular fashion), there are going to be many cases that cannot be reduced in the way the biomedical materialist needs them to be for this objection to go through.

Secondly, even when considering those cases that seem to invoke an individual's exercising their agency in the description (and assuming that this capacity is wholly brain-bound), it seems that explanations of the deficit in an individual's affective capabilities will still need to make ineliminable reference to the way the environment is set up. After all, a deficit in neurocircuitry implicated in motivated action can only determine a deficit in hedonic capability when it is responsible for a failure of an affective scaffold to enhance an individual's affective capability. To put it another way, a deficit in motivation does not by itself entail any change in either hedonic capacity or hedonic sustainability. Such a connection must be mediated by a change in the supportive role of the environ-

7. I thank an anonymous reviewer for Ergo for bringing this objection to my attention. 
ment, meaning that the environment itself is explanatorily indispensable, even in these cases.

So NDC is established. All that is now left to do is demonstrate that such a conclusion extends to the impairment of this capability as well.

\section{Situating Anhedonia}

Let us assume that the evidence above has convinced you that you should grant me NDC (at least for the sake of argument). We can now stop distinguishing between the two options for the characteristic affective capability involved in anhedonia. Take whichever position you prefer, or remain neutral if you wish. Call the capability actually characteristic of anhedonia 'the hedonic capability'. We know two important facts about the hedonic capability, whatever it may turn out to be. Firstly, its diminishment or loss is the defining psychological feature of anhedonia. Secondly, it is generally partially dependent on affective scaffolds (more precisely, an appropriately supportive affective niche) for its existence, or at least the degree to which a certain agent is able to exercise it. The extent to which this is the case will vary, but the hedonic capability is, in general, significantly enhanced by the presence of suitable affective scaffolds (to the degree that it would be unrecognisable in their absence). This suggests that the physical basis of the hedonic capability is not in general to be found solely in the brain. So, is this sufficient to make the further claim that the physical basis of anhedonia (i.e., the loss or diminishment of the hedonic capability) is, consequently, not generally to be found solely in the brain either?

Certainly, the main claim of Section 4 seems to speak strongly in favour of it. If the physical basis of some capability is generally, in part, to be found in the environment, then it seems likely that the physical basis of the diminishment of that capability will also generally, in part, be found in the environment. That is, if some capability is significantly enhanced by the presence of certain material and social resources in the surrounding environment, then it stands to reason that its diminishment will sometimes be explicable only with reference to the loss or diminishment of those same resources.

But we should not proceed so hastily. Firstly, it seems strange to speak of the physical basis of a diminishment in a capability - it sounds curiously close to speaking of the physical basis of an absence (which sounds like nonsense). Secondly, is it not possible that, as it turns out, anhedonia is always, or nearly always the outcome of an issue in the neurological dimensions of the hedonic capability's physical basis? Although I have perhaps secured the conclusion that the physical basis of anhedonia is possibly not solely biological, I have failed to demonstrate that this is ever so (or so often enough to be interesting). 
On the first point, the worry seems to rest on a mild ambiguity in the way I have been speaking so far. When I speak of the physical basis of a phenomenon, I am referring to the physical (in a broad sense of the term that includes the biological) entities and processes that interact to produce the phenomenon in question. So the claim that the physical basis of anhedonia is not to be found solely in the brain is to be read as something like 'the entities and processes that interact to produce anhedonia are not to be found solely in the brain'. My claim is that these entities and processes may include elements of an affective niche that has been impoverished in such a way that it is less capable, or even incapable, of supporting the hedonic capability in the manner it otherwise could. The operations and function of the affective niche of an anhedonic person have, in the general case, been disrupted so as to limit or eliminate its ability to scaffold the hedonic capability.

It seems that I must concede the second point to some degree. The reason why I have made reference throughout this paper to 'the general case' when giving my explanation has been that I seemingly must accept limit cases where the hedonic capability is suitably degraded so as for the case to count as one of anhedonia, but where this is due solely to disruption in the brain activity that (partially) underpins it. While the affective scaffolds remain untouched in such a case, the neurological activity required to support the hedonic capability is disturbed. Thus we would have anhedonia without disruption to the affective niche.

That said, I have two responses that should diminish the force of this objection. Firstly, it seems suspiciously unmotivated to claim that, as it happens, all or even the majority of cases of significant diminishment of the hedonic capability (read: anhedonia) are to be explained only with reference to the brain-based enablers and enhancers of the hedonic capability. The only obvious reason for doing so is that one already endorses biomedical materialism, which is simply to beg the question at issue. The possibility I have raised here entails an obligation for researchers to take seriously the idea that many cases of anhedonia are partially based in disturbances to the individual's wider affective niche, and not simply their head. Further empirical study may, naturally, prove me wrong. Maybe affective niches do not scaffold the hedonic capability to a sufficient degree to account for an interesting range of cases. But (and this is key), to establish this, empirical researchers must first take the alternative possibility seriously in a way that they have not yet done.

Current research that investigates the physical bases of anhedonia discuss only neurobiological processes, states, and properties (for a systematic overview of the literature that exhibits exactly this feature, see Treadway \& Zald 2011). The overwhelming majority of researchers simply do not consider that the physical bases of anhedonia may not be solely neurobiological. They may (and usually do) accept that the causes of anhedonia can be non-neural, but this is beside 
the point for reasons discussed earlier; biomedical materialists do not have to reject the latter claim, but merely the former. Furthermore, research investigating the psychological capabilities that are diminished in anhedonia (e.g., Fiorito \& Simons 1994; Heller et al. 2009) does not commit itself to any claim regarding those capabilities' physical base (though I, of course, think they should). Thus, the research that would establish how often actual cases of anhedonia have their basis solely in neurology has simply not been done; existing research either assumes that this is always the case, or operates at a level of abstraction that does not empirically establish it one way or another. The possibility I have identified is grounded in well-evidenced (though only indirectly relevant) empirical claims about the pervasively situated nature of human affective capabilities; it is hardly so speculative as to warrant summary dismissal.

Secondly, the reciprocally interactive relationship between humans and their affective scaffolds complicates such a picture. It is hard to envisage how a diminished hedonic capability that is perhaps initially based solely in the brain could fail for long to disturb an individual's connection to their occupied affective niche. Lower hedonic capacity or hedonic sustainability regularly causes individuals to give up on previously enjoyable activities and results in them pushing other people away (as well as other people simply avoiding engaging with them). But when that occurs, the diminished capability will not only be reflected in, but also reinforced or worsened by the state of the affective niche that it has 'helped' to impoverish. ${ }^{8}$ The upshot here is that even the tricky limit cases mentioned above are unlikely to remain fully describable as such for long - the relationships involved between brain and world are simply too interdependent.

A related worry presents itself. The example in what follows is drawn from Bechtel (2009). One might be concerned that I have bought my conclusion too cheaply. Imagine a typical car. One of its capabilities (that is, one of the things it can 'do') is move forwards. Call this 'the moving capability'. As in the case of the hedonic capability, this capability is enhanced, indeed made possible, by a variety of external resources that scaffold it. The moving capability requires, amongst other things, relatively smooth, well maintained roads, petrol in the tank, a driver, perhaps (occasionally, one hopes) mechanics, and so on. It also requires an engine. Now, it makes sense to think that, while such external resources are indeed necessary for the existence and characteristic quality of the moving capability, there is clearly a sense in which the engine is more central to its realisation. The engine is a necessary element of the moving capability, and could only be replaced by something that is very similar to it. But the external require-

8. Note that this observation cuts both ways-disturbances in affective niches will not go unreflected in neural dynamics for long, further degrading the affective capabilities that were once scaffolded. 
ments are multiply realisable - various kinds of relatively even roads would do, as would many different kinds of petrol, and a wide variety of drivers.

On the basis of this, it might seem plausible to say the following. In the case of the moving capability, the engine is the locus of control; it is of primary importance in the realisation of the capability. Further, this suggests that the mechanism that produces the moving capability is centred on the engine (and perhaps the wider car). Certainly, this mechanism can only realise the moving capability in the right environmental conditions (sodden, muddy grass on a steep hill, for instance, will stop the car in its tracks), but this does not imply that the mechanism itself is in any sense to be found in the wider environment. Hence, one might say that all that is really important in the analysis of the moving capability is exhausted by looking at the car itself-the environment is a relatively dull added extra. And, so the objection will go, everything I have said about the car and the moving capability applies also to the brain and the hedonic capability. Everything important in the realisation of the hedonic capability is going on in, or is mediated by, the brain.

The issue with this concern is that it misconstrues what I need to secure my main claim. I can happily grant everything that the above analogy might suggest. One may think that claiming that the hedonic capability is environmentally scaffolded is to imply that the mechanism of its realisation is to be (partially) found in the wider environment. This may be true; it depends upon how exactly affective scaffolding operates, and how we ought to demarcate cognitive mechanisms. If so, we should either reinterpret or reject the car analogy. But I need not commit to anything like that picture here.

I will grant for the sake of argument that the car analogy is entirely accuratethe mechanism responsible for the realisation of the hedonic capability is localised in the brain, though is dependent on suitable worldly circumstances to operate properly. Now extend the original analogy -imagine that the car fails to move forward, or begins to do so slowly and with great strain. Independent of any further information, it would be patently illegitimate of me to assume that the engine is broken. Perhaps the surface is poor, or the driver is misusing the clutch. Likewise, if we envisage or perceive a case where the hedonic capability is not being realised, or is being realised only weakly, it is illegitimate of us to assume that the problem lies in the brain, absent any further information. Perhaps the individual in question has been excluded from a significant social network, or have (for some reason) grown affectively insensitive to some other activity they used to partake in to maintain or enable a good mood (or, more likely, a multitude of such activities). Perhaps they are simply unable to engage with previously supportive elements of their affective niche because they have no time, or lack other required resources.

Even if we grant that the brain is the locus of control of the hedonic capabil- 
ity (and it is not obvious that we should), it still requires a whole collection of external resources to effectively realise it. And since anhedonia just is (according to both of the dominant psychological theories) the lack or diminishment of the hedonic capability, the source of that diminishment is irrelevant to identifying cases of anhedonia. Since we can demonstrate partial dependence of that capability on an individual's affective niche in general, we must allow suitable disturbances or disruptions to that niche as potential (partial) bases of anhedonia.

Let me make the point another way. Ruth Millikan (2013) distinguishes between a mechanism or system malfunctioning and it simply failing to perform its function. In the former case, the mechanism fails to execute its function despite 'normal conditions' 9 obtaining, due to "abnormalities in the constitution of the device itself" (Millikan 2013: 40). In the latter case, it is prevented from performing its function due to abnormal circumstances obtaining. This corresponds intuitively to the difference between an otherwise healthy 30-year-old person in a completely healthy environment suddenly having a heart attack, and the heart failing to pump blood after it has been removed from a living organism. In the first case the heart is naturally thought to have malfunctioned, in the second everything is fine with the heart-it simply fails to perform its function because it is not embedded in remotely convivial circumstances.

Even if the brain genuinely is the locus of control for the hedonic capability, and even if the mechanism responsible for the capability's realisation is properly specified internally, my main thesis is still secure. If I am right that the hedonic capability is typically dependent for its existence and extent on an individual's particular affective niche, then the realisation of anhedonia does not generally depend on the brain, or a particular neurological subsystem malfunctioning, in Millikan's sense (though this may sometimes occur initially). Genuine cases of anhedonia may equally well arise in a situation where the relevant mechanism simply fails to perform its function, due to an unsuitable affective niche. The hedonic capability is diminished or lost in both cases. And, certainly, the course of anhedonia will tend to reflect both neural and environmental dynamics. To the degree that you endorse either of the contemporary psychological perspectives on anhedonia therefore, there is no good reason to think that only solely neurologically based anhedonia (if such a condition even exists) is 'the real thing'.

What might this result tell us about the prospects for refuting biomedical materialism across the board? A full answer to this question is well beyond the scope of this paper, but I shall conclude by explicating the following general strategy that one might adopt given the form this paper has taken.

9. Take this notion intuitively here; what exactly Millikan intends by the term 'normal conditions' is complex, subtle, and not important for our purposes. 
Identify a psychiatric condition or symptom that is characterised by the diminishment or absence of a certain psychological capacity.

Argue that this capacity depends on extra-neural processes, events, or properties.

Defend the view that it is the absence of these extra-neural entities that explains the diminished capacity in an interesting range of cases.

I cannot say for sure what the prospects of such a general strategy are, though I will conclude by noting a few key features.

Firstly, it is piecemeal; it does not attempt to demonstrate that biomedical materialism is false of all psychiatric conditions or symptoms, but merely one at a time. This is both a blessing and a curse. It is a blessing because it focuses attention on important concrete cases, where arguments can be made that draw on well-established and specific research literatures, but it is a curse because a recalcitrant biomedical materialist might simply suggest that such cases are exceptions, and not the rule. A lot of work would need to be done to demonstrate otherwise.

Secondly, it requires that we persuasively characterise psychiatric conditions and symptoms in terms of a loss of identifiable psychological capacities. This is certainly common practice for many interesting symptoms; for instance, formal thought disorder in Schizophrenia (see Yalincetin, Bora, Binbay, Ulas, Akdede, \& Alptekin 2017). But it is non-trivial for symptoms that seem to add to rather than detract from psychological experience, such as hallucinations. Although a view that attributed hallucinations to a failure to properly attenuate certain kinds of prediction error signal might be able to do the necessary work (Horga, Schatz, Abi-Dargham, \& Peterson 2014), it is doubtful that we can manage such a trick across the board. So this strategy's prospects will be limited to some degree or another.

Finally (and more positively), this strategy has a few advantages when compared to attempts to make similar kinds of cases in the literature. It compares favourably to, for instance, Zoe Drayson (2009), Mark Sprevak (2011), and Miriam Kyselo (2016) in that it does not simply give a competing characterisation of a psychiatric entity in terms of a situated or externalist theory that is inconsistent with biomedical materialism. Rather, it explicitly makes a case that such an explanation is the only one available, given the psychological evidence. We are not merely surveying the insights that situated cognition might give us, but explicitly arguing that a situated framework is necessary for successful vertical explanation of the disorder or symptom in question.

Further, it establishes a considerably stronger form of externalism than, for instance, that argued for by Will Davies (2016). Davies suggests that many existing psychiatric categories are externalist, in the sense that criteria for correct 
application of these concepts require entities that do not supervene on a person's neurology. This, however, is a relatively weak (though certainly interesting) form of externalism; it does not establish that the psychological features of the disorder itself exhibit any interesting dependence on non-neural features, but only that our concepts of mental disorder make ineliminable reference to such features. On Davies' view, it could still be true that everything that made a person with, say, depression feel especially sad supervened on that person's neurology. It would simply be the case that we could not diagnose depression per se unless the degree of sadness exhibited deviated sufficiently from the norm. Since statistical norms such as this are external to neurology, this would make depression externalist in Davies' sense, but in a way that would not, presumably, affect one's prior view on whether researchers were right to seek out the underpinnings of depression solely within neurobiology.

Rather than conceptual externalism, this paper has argued that good vertical explanations of anhedonia (characterised as the loss of a particular affective capability) must include reference to non-neural entities that exist in a person's wider environment. This explicitly does undercut research that seeks to provide such explanations in wholly neurobiological terms. And if such a strategy were to succeed in a wide range of cases, we would have established results that posed a significant challenge to both the theory and practice of biomedical materialism.

\section{Acknowledgments}

I thank Lisa Bortolotti, Iain Law, Will Davies, Joel Krueger, Matt Parrott, Rachel Upthegrove, Mae Rohani, and Hanna Pickard for reading innumerable drafts of this paper between them, and for their meticulous and extremely helpful feedback. I would also like to thank Scott Sturgeon, Ema Sullivan-Bissett, Kash Sunghuttee, Michael Roberts, Eugenia Lancelotta, Tom Davies, Lauren GrahamSymonds, Casey Elliott, Matilde Aliffi, Stew Yarlett, Em Walsh, Maja Spener, and Anneli Jefferson for extremely helpful discussions over the last four years on the topics covered in this paper. Finally, I extend my gratitude to two anonymous reviewers for Ergo, for their clear and extremely useful suggestions regarding both the detail and scope of the paper.

\section{References}

Adams, Fred and Kenneth Aizawa (2001). The Bounds of Cognition. Philosophical Psychology, 14(1), 43-64.

Aizawa, Kenneth (2010). The Coupling-Constitution Fallacy Revisited. Cognitive Systems Research, 11(4), 332-342. https://doi.org/10.1016/j.cogsys.2010.07.001 
Bargh, John A. and Idit Shalev (2012). The Substitutability of Physical and Social Warmth in Daily Life. Emotion, 12(1), 154-162. https://doi.org/10.1037/a0023527

Barrett, Lisa F. (2012). Emotions Are Real. Emotion, 12(3), 413-429.

Barrett, Lisa F. (2014). The Conceptual Act Theory: A Precis. Emotion Review 6(4), 292297.

Bechtel, William (2009). Explanation: Modularity, Mechanism, and Situated Cognition. In Philip Robbins and Murat Aydede (Eds.), The Cambridge Handbook of Situated Cognition (155-170). Cambridge University Press. https://doi.org/10.1017/ cbo9780511816826.009

Berenbaum, Howard and Janice Connelly (1993). The Effect of Stress on Hedonic Capacity. Journal of Abnormal Psychology, 102(3), 474-481. https://doi.org/10.1037//0021843x.102.3.474

Bircher, Johannes (2005). Towards a Dynamic Definition of Health and Disease. Medicine, Healthcare and Philosophy, 8(3), 335-341

Burleson, Brant R. (1985). The Production of Comforting Messages: Social-Cognitive Foundations. Journal of Language and Social Psychology, 4(3\&4), 253-273. https:// doi.org/10.1177/0261927x8543006

Clark, Andy and David Chalmers (1998). The Extended Mind. Analysis, 58(1), 7-19.

Colombetti, Giovanna (2012). Psychopathology and the Enactive Mind. In K. W. M. Fulford, Martin Davies, Richard Gipps, George Graham, John Sadler, Giovanni Stanghellini, and Tim Thornton (Eds.), The Oxford Handbook of Philosophy of Psychiatry (1083-1101). Oxford University Press. https://doi.org/10.1093/oxford$\mathrm{hb} / 9780199579563.013 .0063$

Colombetti, Giovanna (2017). The Embodied and Situated Nature of Moods. Philosophia, 45(4), 1437-1451. https://doi.org/10.1007/s11406-017-9817-0

Colombetti, Giovanna and Joel Krueger (2015). Scaffoldings of the Affective Mind. Philosophical Psychology, 28(8), 1157-1176. https://doi.org/10.1080/09515089.2014.976334

Davies, Will (2016). Externalist Psychiatry. Analysis, 76(3), 290-296.

Der-Avakian, Andre and Athina Markou (2012). The Neurobiology of Anhedonia and Other Reward-Related Deficits. Trends in Neuroscience, 35(1), 68-77. https://doi. org/10.1016/j.tins.2011.11.005

Drayson, Zoe (2009). Embodied Cognitive Science and its Implications for Psychopathology. Philosophy, Psychiatry \& Psychology, 16(4), 329-340. https://doi.org/10.1353/ ppp. 0.0261

Drayson, Zoe (2012). The Uses and Abuses of the Personal/Subpersonal Distinction. Philosophical Perspectives, 26(1), 1-18. https://doi.org/10.1111/phpe.12014

Dworkin, Robert H. and Kathleen Saczynski (1984). Individual Differences in Hedonic Capacity. Journal of Personality Assessment, 48(6), 620-626. https://doi.org/10.1207/ s15327752jpa4806_8

Elliott, Dave, Sam Carr, and Dave Savage (2004). Effects of Motivational Music on Work Output and Affective Responses During Sub-Maximal Cycling of a Standardized Perceived Intensity. Journal of Sport Behavior, 27(2), 134-147.

Elliott, Dave, Sam Carr, and Duncan Orme (2005). The Effect of Motivational Music on Sub-Maximal Exercise. European Journal of Sport Science, 5(2), 97-106. https://doi. org/10.1080/17461390500171310

Fiorito, Evelyn R. and Robert F. Simons (1994). Emotional Imagery and Physical Anhedonia. Psychophysiology, 31(5), 513-521. https://doi.org/10.1111/j.1469-8986.1994. tb01055.x 
Fuchs, Thomas (2001). Melancholia as a Desynchronization: Towards a Psychopathology of Interpersonal Time. Psychopathology, 34(4), 179-186. https://doi. org/10.1159/000049304

Fuchs, Thomas (2009). Embodied Cognitive Neuroscience and its Consequences for Psychiatry. Poiesis \& Praxis, 6(3-4), 219-233. https://doi.org/10.1007/s10202-008-0068-9

Gable, Shelly L. and Harry T. Reis (2010). Good News! Capitalizing on Positive Events in an Interpersonal Context. In Mark P. Zanna (Ed.), Advances in Experimental Social Psychology (Vol. 42, 195-257), Elsevier. https://doi.org/10.1016/s0065-2601(10)420043

Germans, Marja K. and Ann M. Kring (2000). Hedonic Deficit in Anhedonia: Support for the Role of Approach Motivation. Personality and Individual Differences, 28(4), 659672. https://doi.org/10.1016/s0191-8869(01)00074-5

Griffiths, Paul and Andrea Scarantino (2009). Emotions in the Wild: The Situated Perspective on Emotion. In Philip Robbins and Murat Aydede (Eds.), The Cambridge Handbook of Situated Cognition (437-453). Cambridge University Press. https://doi. org/10.1017/cbo9780511816826.023

Heller, Aaron S., Tom Johnstone, Alexander J. Shackman, Sharee N. Light, Michael J. Peterson, Gregory G. Kolden, . . . Richard J. Davidson (2009). Reduced Capacity to Sustain Positive Emotion in Major Depression Reflects Diminished Maintenance of Fronto-Striatal Brain Activation. PNAS, 106(52), 22445-22450. https://doi. org/10.1073/pnas.0910651106

Hofmann, Stefan G. (2014). Interpersonal Emotion Regulation Model of Mood and Anxiety Disorders. Cognitive Therapy and Research, 38(5), 483-492. https://doi. org/10.1007/s10608-014-9620-1

Horga, Guillermo, Kelly C. Schatz, Anissa Abi-Dargham, and Bradley S. Peterson (2014). Deficits in Predictive Coding Underlie Hallucinations in Schizophrenia. The Journal of Neuroscience, 34(24). 8072-8082. https://doi.org/10.1523/jneurosci.0200-14.2014

Huber, Lara and Lara K. Kutschenko (2009). Medicine in a Neurocentric World: About the Explanatory Power of Neuroscientific Models in Medical Research and Practice. Medicine Studies, 1(4), 307-313. https://doi.org/10.1007/s12376-009-0036-2

Kaviani, Hossein, Jeffrey A. Gray, Stuart A. Checkley, Peter W. Raven, G. D. Wilson, and V. Kumari (2004). Affective Modulation of the Startle Response in Depression: Influence of the Severity of Depression, Anhedonia, and Anxiety. Journal of Affective Disorders, 83(1), 21-31. https://doi.org/10.1016/j.jad.2004.04.007

Köhler, Stephan, Katharina Cierpinsky, Golo Kronenberg, and Mazda Adli (2016). The Serotinergic System in the Neurobiology of Depression: Relevance for Novel Antidepressants. Journal of Psychopharmacology, 30(1), 13-22. https://doi. org/10.1177/0269881115609072

Koole, Sander L. (2009). The Psychology of Emotion Regulation: An Integrative Review. Cognition and Emotion, 23(1), 4-41. https://doi.org/10.1080/02699930802619031

Koole, Sander L. and Lotte Veenstra (2015). Does Emotion Regulation Occur Only Inside People's Heads? Toward a Situated Cognition Analysis of Emotion-Regulatory Dynamics. Psychological Inquiry, 26(1), 61-68. https://doi.org/10.1080/104784 0x.2015.964657

Koole, Sander L., Mandy T. A. Sin, and Iris K. Schneider (2014). Embodied Terror Management: Interpersonal Touch Alleviates Existential Concerns among Individuals with Low Self-Esteem. Psychological Science, 25(1), 30-37. https://doi. org/10.1177/0956797613483478 
Koole, Sander L., Thomas L. Webb, and Paschal L. Sheeran (2015). Implicit Emotion Regulation: Feeling Better without Knowing Why. Current Opinion in Psychology, 3, 6-10. https://doi.org/10.1016/j.copsyc.2014.12.027

Kovács, József (1998). The Concept of Health and Disease. Medicine, Healthcare and Philosophy, I(1), 31-39.

Kwon, Yoon-Hee (1991). The Influence of the Perception of Mood and Self-Consciousness on the Selection of Clothing. Clothing and Textiles Research Journal, 9(4), 41-46. https://doi.org/10.1177/0887302x9100900406

Kyselo, Miriam (2016). The Enactive Approach and Disorders of the Self - the Case of Schizophrenia. Phenomenology \& the Cognitive Sciences, 15(4), 591-616. https://doi. org/10.1007/s11097-015-9441-z

Law, Iain and Heather Widdows (2008). Conceptualising Health: Insights from the Capability Approach. Health Care Analysis, 16(4), 303-314. https://doi.org/10.1007/ s10728-007-0070-8

Lieberman, Matthew D. (2011). Why Symbolic Processing of Affect Can Disrupt Negative Affect: Social Cognitive and Affective Neuroscience Investigations. In Alexander Todorov, Susan T. Fiske, and Deborah A. Prentice (Eds.), Social Neuroscience: Toward Understanding the Underpinnings of the Social Mind (188-209). Oxford University Press. https://doi.org/10.1093/acprof:oso/9780195316872.003.0013

Lim, Harry B. T., Greg Atkinson, Costas I. Karageorghis, and Martin Eubank (2009). Effects of Differentiated Music on Cycling Time Trial. International Journal of Sports Medicine, 30(6), 435-442. https://doi.org/10.1055/s-0028-1112140

Lima-Ojeda, Juan M., Rainer Rupprecht, and Thomas C. Baghai (2017). Neurobiology of Depression: A Neurodevelopmental Approach. The World Journal of Biological Psychiatry, 19(5). https://doi.org/10.1080/15622975.2017.1289240

Liu, Wen-hua, Raymond C. K. Chan, Ling-zhi Wang, Jia Huang, Eric F. C. Cheung, Qi-yong Gong, and Jackie K. Gollan (2011). Deficits in Sustaining Reward Responses in Subsyndromal and Syndromal Major Depression. Progress in NeuroPsychopharmacology and Biological Psychiatry, 35(4), 1045-1052. https://doi. org/10.1016/j.pnpbp.2011.02.018

Mallorquí, Aida, Gonçalo Padrao, and Antoni Rodriguez-Fornells (2014). Electrophysiological Signatures of Reward Processing in Anhedonia. In Michael S. Ritsner (Ed.), Anhedonia: A Comprehensive Handbook Volume I: Conceptual Issues and Neurobiological Advances (245-278). Springer. https://doi.org/10.1007/978-94-017-85914_11

Manian, Nanmathi and Marc H. Bornstein (2009). Dynamics of Emotion Regulation in Infants of Clinically Depressed and Nondepressed Mothers. The Journal of Child Psychology and Psychiatry, 50(11), 1410-1418. https://doi.org/10.1111/j.14697610.2009.02166.x

Marroquin, Brett (2011). Interpersonal Emotion Regulation as a Mechanism of Social Support in Depression. Clinical Psychology Review, 31(8), 1276-1290. https://doi. org/10.1016/j.cpr.2011.09.005

Meehl, Paul E. (1975). Hedonic Capacity: Some Conjectures. Bulletin of the Menninger Clinic, 39(4), 295-307.

Millikan, Ruth G. (2013). Reply to Neander. In Dan Ryder, Justine Kingsbury, and Kenneth Williford (Eds.), Millikan and Her Critics (37-40), Wiley-Blackwell. https://doi. org/10.1093/mind/fzv017 
Moody, Wendy, Peter Kinderman, and Pammi Sinha (2010). An Exploratory Study: Relationships Between Trying on Clothing, Mood, Emotion, Personality and Clothing Preference. Journal of Fashion Marketing and Management: An International Journal, 14(1), 161-179. https://doi.org/10.1108/13612021011025483

Myerson, Abraham (1922). Anhedonia. The American Journal of Psychiatry, 2, 87-103

Oyebode, Femi (2015). Sims' Symptoms in the Mind: Textbook of Descriptive Psychopathology (5th ed.). Saunders Elsevier.

Pizzagalli, Diego A., Ryan Bogdan, Kyle G. Ratner, and Allison L. Jahn (2007). Increased Perceived Stress is Associated with Blunted Hedonic Capacity: Potential Implications for Depression Research. Behaviour Research and Therapy, 45(11), 2742-2753. https://doi.org/10.1016/j.brat.2007.07.013

Pizzagalli, Diego A., Dan Iosifescu, Lindsay A. Hallett, Kyle G. Ratner, and Maurizio Fava (2008). Reduced Hedonic Capacity in Major Depressive Disorder: Evidence from a Probabilistic Reward Task. Journal of Psychiatric Research, 43(1), 76-87. https://doi.org/10.1016/j.jpsychires.2008.03.001

Rizvi, Sakina J., Diego A. Pizzagalli, Beth A. Sproule, and Sidney H. Kennedy (2016). Assessing Anhedonia in Depression: Potentials and Pitfalls. Neuroscience and Biobehavioral Reviews, 65, 21-35. https://doi.org/10.1016/j.neubiorev.2016.03.004

Robbins, Philip and Murat Aydede (2009). A Short Primer on Situated Cognition. In Philip Robbins and Murat Aydede (Eds.), The Cambridge Handbook of Situated Cognition (3-10). Cambridge University Press. https://doi.org/10.1017/cbo9780511816826.001

Roberts, Michael (2017). Phenomenological Constraints: A Problem for Radical Enactivism. Phenomenology \& the Cognitive Sciences, 17(2), 375-399. https://doi. org/10.1007/s11097-017-9511-5

Samur, Dalya., Mattie Tops, Caroline Schlinkert, Markus Quirin, Pim Cuijpers, and Sander L. Koole (2013). Four Decades of Research on Alexithymia: Moving Toward Clinical Applications. Frontiers of Psychology, 4, 861. https://doi.org/10.3389/ fpsyg.2013.00861

Saxbe, Darby and Rena L. Repetti (2010). For Better or Worse? Coregulation of Couples' Cortisol Levels and Mood States. Journal of Personality and Social Psychology, 98(I), 92-103. https://doi.org/10.1037/a0016959

Sbarra, David A. and Cindy Hazan (2008). Coregulation, Dysregulation, Self-Regulation: An Integrative Analysis and Empirical Agenda for Understanding Adult Attachment, Separation, Loss and Recovery. Personality and Social Psychology Review, 12(2), 141-167. https://doi.org/10.1177/1088868308315702

Shapiro, Lawrence (2011). Embodied Cognition. Routledge.

Skånland, Marie S. (2013). Everyday Music Listening and Affect Regulation: The Role of $\mathrm{MP}_{3}$ Players. International Journal of Qualitative Studies on Health and Well-being, 8(1), 20595. https://doi.org/10.3402/qhw.v8i0.20595

Sonuga-Barke, Edmund J. S. (2017). Commentary: Extraordinary Environments, Extreme Neuroplasticity and Mental Disorder - Reflections on Pathways from Adversity to Mental Disorder Prompted by McCrory, Gerin, and Viding (2017). The Journal of Child Psychology and Psychiatry, 58(4), 358-36o. https://doi.org/10.1111/jcpp.12726

Sprevak, Mark (2011). Neural Sufficiency, Reductionism, and Cognitive Neuropsychiatry. Philosophy, Psychiatry \& Psychology, 18(4), 339-344. https://doi.org/10.1353/ ppp.2011.0057 
Sterelny, Kim (2010). Minds: Extended or Scaffolded. Phenomenology and the Cognitive Sciences, 9(4), 465-481. https://doi.org/10.1007/s11097-010-9174-y

Tomarken, Andrew J. and Anita D. Keener (1998). Frontal Brain Asymmetry and Depression: A Self-Regulatory Perspective. Cognition and Emotion, 12(3), 387-420. https:// doi.org/10.1080/026999398379655

Treadway, Michael T., Nicholas A. Bossaller, Richard C. Shelton, and David H. Zald (2012). Effort-Based Decision-Making in Major Depressive Disorder: A Translational Model of Motivational Anhedonia. Journal of Abnormal Psychology, 121(3), 553558. https://doi.org/10.1037/a0028813

Treadway, Michael T. and David H. Zald (2011). Reconsidering Anhedonia in Depression: Lessons from Translational Neuroscience. Neuroscience and Biobehavioral Reviews, 35(3), 537-555. https://doi.org/10.1016/j.neubiorev.2010.06.006

Valdez, Patricia and Albert Mehrabian (1994). Effects of Color on Emotions. Journal of Experimental Psychology: General, 123(4), 394-409. https://doi.org/10.1037//00963445.123.4.394

Varga, Somogy (2016). Interaction and Extended Cognition. Synthese, 193(8), 2469-2496.

Varga, Somogy and Joel Krueger (2013). Background Emotions, Proximity and Distributed Emotion Regulation. Review of Philosophy and Psychology, 4(2), 271-292. https://doi.org/10.1007/s13164-013-0134-7

Vogt, Julia, Ljubica Lozo, Ernst H. W. Koster, and Jan De Houwer (2010). On the Role of Goal Relevance in Emotional Attention: Disgust Evokes Early Attention to Cleanliness. Cognition and Emotion, 25(3), 466-477. https://doi.org/10.1080/02699931.2010 .532613

Wilson, Robert A. and Andy Clark (2009). How to Situate Cognition: Letting Nature Take its Course. In Philip Robbins and Murat Aydede (Eds.), The Cambridge Handbook of Situated Cognition (55-77). Cambridge University Press. https://doi.org/10.1017/ cbo9780511816826.004

Wohleb, Eric S., Tina Franklin, Masaaki Iwata, and Ronald S. Duman (2016). Integrating Neuroimmune Systems in the Neurobiology of Depression. Nature Reviews Neuroscience, 17(8), 497-511. https://doi.org/10.1038/nrn.2016.69

Yalincetin, Berna, Emre Bora, Tolga Binbay, Halis Ulas, Berna Binnur Akdede, and Koksal Alptekin (2017). Formal Thought Disorder in Schizophrenia and Bipolar Disorder: A Systematic Review and Meta-Analysis. Schizophrenia Research, 185, 2-8. https://doi.org/10.1016/j.schres.2016.12.015

Zachar, Peter (2000). Psychological Concepts and Biological Psychiatry. John Benjamins.

Zaki, Jamil, Jessica Schirmer, and Jason P. Mitchell (2011). Social Influence Modulates the Neural Computation of Value. Psychological Science, 22(7), 894-900. https://doi. org/10.1177/0956797611411057

Zaki, Jamil and W. Craig Williams (2013). Interpersonal Emotion Regulation. Emotion, 13(5), 803-810. https://doi.org/10.1037/a0033839 